\title{
REFLEXÕES SOBRE A PONDERAÇÃO DO DIREITO DE IGUALDADE EM FACE AO PRINCÍPIO DA PROPRIEDADE E DA LIVRE INICIATIVA: UM EXAME DA ADI N. 2.649/DF
}

\author{
Debora Bonat ${ }^{1}$ \\ Fabiano \\ Hartmann \\ Peixoto $^{2}$
}

\begin{abstract}
Resumo
O presente artigo tem como objetivo analisar o conteúdo de decisão judicial onde houve uma colisão de princípios, relacionando seus elementos às nuances de vertentes kantianas e hegelianas. Em maio de 2008 o Supremo Tribunal Federal (STF) julgou, por maioria, improcedente ação direta de inconstitucionalidade proposta pela ABRATI - Associação Brasileira das Empresas de Transporte Interestadual, Intermunicipal e Internacional de Passageiros em face da Lei 8.899/1994 que concedeu dois assentos com passe-livre para pessoas com deficiência. Buscando estruturar um raciocínio pelo método dedutivo, observando-se os limites espaciais que circunscrevem o formato do trabalho, serão tratados contornos das teorias dos autores supramencionados. Após, o trabalho avaliará a solução de aplicação da máxima da proporcionalidade. Finalmente, refletirá sobre as propostas teóricas abordadas e a decisão concretamente efetivada pelo Supremo Tribunal Federal.
\end{abstract}

Palavras-Chaves: Direito - Princípios - Proporcionalidade - Ponderação - Igualdade

\section{INTRODUÇÃO}

O trabalho se propõe a encaminhar respostas ao questionamento que (res)surgiu ao se revisitar e fazer uma nova análise do conteúdo de decisão judicial do Supremo Tribunal Federal (STF) que julgou, por maioria, improcedente ação direta de inconstitucionalidade proposta pela ABRATI - Associação Brasileira das Empresas de Transporte Interestadual, Intermunicipal e Internacional de Passageiros em face da Lei 8.899/1994 que concede dois assentos com passe-livre para pessoas com deficiência.

A problemática apresenta uma aparente colisão de princípios solucionada com

\footnotetext{
${ }^{1}$ Doutora em Direito pela UnB. Professora de Direito e Coordenadora de Pesquisa da Faculdade de Direito CESUSC.E-mail: debora_bt@hotmail.com
} vol.09, n. 03, Rio de Janeiro, 2016. pp. 
possíveis ressalvas sob a ótica teórica da proporcionalidade bem como a referida decisão permite relacionar seus elementos a traços marcantes e interessantes de vertentes kantianas e hegelianas do pensamento.

Para buscar um encaminhamento nessa nova análise, o presente trabalho partirá de uma abordagem descritiva e instrumental inicial e três reflexões sobre abordagens teóricas. A primeira buscará apresentar elementos que demonstram, numa específica atividade jurisdicional brasileira, tradições fortemente ligadas à teoria kantiana, com os consequentes riscos impostos ao papel do Judiciário em uma sociedade contemporânea tão complexa. Determinar conteúdos a partir de abstrações generalizadoras, desprezando qualquer tipo de envolvimento com a prática social e com os conflitos que ela desencadeia, faz com que o aparato jurisdicional perca legitimidade e caia no vazio.

A segunda abordagem, realizada a partir da constatação de um ambiente com pluralidade de ideias e da necessária reflexão sobre o particularismo, que a sociedade contemporânea impõe, permitirá sob um outro enfoque a análise da atividade jurisdicional (posto que não a inviabiliza). A chave para tal abordagem é a imposição da função das instituições na prevenção da desagregação social e a determinação da realização da consciência ética do bem comum. Entretanto, ambas as abordagens impõem uma intensa atividade valorativa, que é um problema quando se fala em atividade jurisdicional.

Assim, seria justificada uma terceira abordagem, na qual serão apresentadas contribuições que a proporcionalidade de Alexy poderia trazer a construção da decisão judicial que devem ser feitas num cenário como o da ADI em questão. Para o problema das valorações, Alexy propõe a argumentação jurídica, como atividade linguística e como possibilidade de busca de correção. Assim, havendo colisões princípiológicas (normas com caráter de mandamentos de otimização), a solução se dará por uma atividade discursiva que buscará a correção de enunciados normativos, com fundamento da chamada tese do caso especial. Alexy, portanto, com uma teoria analítico-normativa do discurso jurídico que, face a finitude de argumentos jurídicos, terá base a identificação de argumentos morais, mas que procedimentalmente ainda permitem atingir o objetivo maior da tomada de decisões: a necessária exigência de justificação. Com a passagem por essas etapas, pretende o presente trabalho encaminhar alguns entendimentos que possam contribuir para reflexões sobres os riscos e possibilidades em decisões judiciais com exigência de intensa valoração.

\footnotetext{
${ }^{2}$ Doutor em Direito pela Universidade de Brasília - UnB. Professor Permanente de Direito Privado e Relações Econômicas da Faculdade de Direito da Universidade de Brasília -UnB. E-mail: fabiano_hp@hotmail.com
} vol.09, n. 03, Rio de Janeiro, 2016. pp. 


\section{A ADI N. 2.649/DF}

Alegava a ABRATI - Associação Brasileira das Empresas de Transporte Interestadual que o benefício (concessão de dois assentos com passe-livre para pessoas com deficiência) trazido pela norma federal (Lei 8.899/1994) seria uma ação de assistência social e como tal precisaria, necessariamente, prever sua fonte de custeio, sob pena de configuração de confisco no domínio privado, caracterizando flagrante desrespeito a livre iniciativa, aos princípios da ordem econômica e ao direito de propriedade. Por fim, sustentava, a requerente, a existência de flagrante desrespeito ao princípio da isonomia, sobrecarregando economicamente a empresa com o ônus de custear um benefício assistencial que, pela sua natureza, "impõe participação de toda a coletividade" (STF, 2008, p. 32). Tal situação inviabilizaria a manutenção da empresa e colocaria em risco a continuidade da prestação do serviço.

A Ministra Carmem Lúcia, relatora da causa, ao proferir seu voto - seguido por todos os demais Ministros com exceção do Ministro Marco Aurélio - ultrapassados os critérios meramente procedimentais para a propositura da ADI (ação direta de inconstitucionalidade), avaliou o contexto social e histórico no qual se encontra inserida a norma protetiva dos direitos das pessoas com deficiência. Ressaltou os termos da Resolução aprovada pela Assembleia Geral da Organização das Nações Unidas que em 1975 proclamou a Declaração dos Direitos das Pessoas Deficientes, assim como, a Convenção sobre os Direitos das Pessoas com Deficiência e seu Protocolo Facultativo, ambos assinados pelo Brasil.

Entendeu que os referidos documentos determinam ao Estado o desenvolvimento de políticas públicas permanentes para a inserção isonômica das pessoas com deficiência nas atividades sociais e laborais, que estão de acordo com o texto constitucional e mais, acabam por reforçar os valores de solidariedade e fraternidade na interpretação das normas constitucionais. O primeiro documento preceitua o alargamento a obrigação estatal abrangendo toda a sociedade a agir conforme a seguinte diretriz: "a cada um segundo sua necessidade" (STF, 2008, p. 43).

Seguindo a fundamentação de seu voto, a Ministra procurou demonstrar que o transporte coletivo é serviço público, sendo o Poder Público o titular de sua execução, podendo prestá-lo mediante regime de concessão ou permissão, conforme artigo 175 da CRFB/88. Caracterizado como serviço público deverá, necessariamente, obedecer as regras específicas de bem estar da sociedade, não existindo, portanto, liberdade ampla, pois é o interesse público que norteia e delimita esta forma de prestação de serviços.

Defendeu a tese de que o titular (empresa concessionária ou permissionária) ao aceitar vol.09, n. 03, Rio de Janeiro, 2016. pp. 
prestar tais serviços está sujeito as mudanças unilaterais de condições pelo Estado e que os riscos do negócio são assumidos pela empresa concessionária ou permissionária. Enfim, afirmou que a necessidade da sociedade que define o conteúdo de tais contratos.

Quanto a livre iniciativa, nos casos de permissionários ou concessionários, entendeu o Tribunal, que sua incidência ocorre somente no momento de constituição da empresa e no da liberdade de contratar ou não com o Estado. Reiterou a disciplina trazida pela Constituição relativa ao atendimento das necessidades sociais no desempenho desta atividade.

Outra questão levantada na ação de inconstitucionalidade pela associação requerente se deu sobre o desrespeito ao princípio da igualdade. Neste sentido, entendeu a relatora:

O princípio jurídico da igualdade é o que a sociedade quer que ele seja. Não é obra de Deuses, nem de formas heterônomas, nem de forças exógenas que se impõem a uma sociedade com explicações místicas... A igualdade no Direito é arte do homem. Por isso o princípio jurídico da igualdade é tanto mais legítimo quanto mais próximo estiver o seu conteúdo da ideia de justiça em que a sociedade acredita na pauta da história e do tempo... No sistema constitucional fundamentado pelo princípio da igualdade materialmente cogitado, o serviço público é prestado de forma a assegurar que a prestação daquela atividade considere a condição subjetiva e mesmo socioeconômica do usuário, a fim de que não se chegue a uma situação de injustiça em que os mais favorecidos, materialmente, recebam os melhores serviços públicos, enquanto exatamente os menos aquinhoados sejam despojados de seus direitos fundamentais por não poderem contar com o mínimo de estrutura de serviços para o seu bem estar.[...] (STF, 2008, p. 48-49)

Afirma que o benefício do passe-livre foi criado com base no princípio da isonomia, inexistindo, portanto, qualquer invalidade quanto ao conteúdo das normas constitucionais.

Por fim, foi examinada a ausência de custeio para a prestação deste benefício. Segundo entendimento da requerente este benefício constituiria uma ação de assistência social necessitando, consequentemente, de indicação da fonte de custeio. O Tribunal entendeu que a determinação obrigatória do custeio refere-se exclusivamente aos benefícios ou serviços de seguridade social que onerem os cofres públicos, portanto, com impacto orçamentário, o que não ocorreria no presente caso, uma vez que a despesa gerada pela concessão do benefício seria repassada aos demais usuários do sistema de transporte coletivo.

Discordou neste ponto, sendo voto vencido, o Ministro Marco Aurélio. Para ele o benefício constitui ação de seguridade social e, portanto, deveria prever sua forma de custeio, depois de comprovada a carência e a deficiência que autorizem o passe livre. Informa ainda que o Estado não pode conceder benefícios gerando despesas somente a terceiros. Em suas palavras: não se pode "cumprimentar com chapéu alheio" (STF, 2008, p. 68).

Dessa forma, avaliando o último argumento, confisco pelo Poder Público e ataque ao princípio da propriedade, entendeu-se que o demonstrativo dos gastos com a concessão do benefício não seria da empresa de transporte, mas sim dos usuários, não existindo, portanto, vol.09, nº. 03, Rio de Janeiro, 2016. pp. 1455 
qualquer tipo de confisco ou atentado ao direito de propriedade. Todavia, permitiu-se a requerente o ingresso de ação adequada para cobrar, caso fosse necessário, valores de um futuro prejuízo.

Não constitui tarefa fácil analisar a possibilidade de fruição de direitos fundamentais em uma sociedade complexa. Tradicionalmente, o Judiciário brasileiro ao examinar tais casos busca em argumentos exclusivamente jurídicos e abstratos, partindo de universalizações, a resolução da demanda, marginalizando a interdisciplinaridade e pouco se importando com as consequências de seus atos jurisdicionais.

\section{AS NUANCES PRINCIPIOLÓGICAS SOB O REFERENCIAL DO UNIVERSALISMO}

A decisão aqui examinada retrata como ponto central a definição do conteúdo do princípio da igualdade como base da possibilidade do Estado intervir na propriedade privada e na atuação comercial de empresas. Afasta a liberdade dos contratos e das regras da livre iniciativa na tentativa de garantir maior estabilidade social, encaminhando os interesses que emanam dos diferentes grupos sociais a atingir "Ideia do Bem".

Como se verá adiante, contemporaneamente na tradição jurídica brasileira ainda são encontrados elementos de uma teoria kantiana. Todavia, esta vertente encontra-se em franca oposição ao papel que o Judiciário deve desempenhar em uma sociedade tão complexa. Determinar conteúdos a partir de abstrações generalizadoras, desprezando qualquer tipo de envolvimento com a prática social e com os conflitos que ela desencadeia, faz com que o aparato jurisdicional perca legitimidade e caia no vazio.

A decisão aqui trazida reflete esta tradicional tendência. Ao avaliar a constitucionalidade, a relatora parte da análise do preâmbulo constitucional indicando os valores eleitos pela sociedade brasileira de maneira abstrata, afirmando ao final que há no texto constitucional a previsão do princípio da solidariedade e que este deve funcionar como cânone interpretativo da igualdade.

Embora o direito possua, como uma de suas fontes, normas gerais e abstratas, estas devem ao ser interpretadas refletir o momento histórico da sociedade, sua economia, suas possibilidades governamentais e suas precariedades sociais privilegiando a fruição real de direito, enfim, atuando de forma a diminuir a concentração de poder e não a mantendo.

A inserção da categorização dos princípios no ordenamento jurídico brasileiro como normas abertas e maleáveis, com alto grau axiológico, poderia ter sido usada como forma de identificação do direito com a realidade, mas não o foi. O Judiciário passou a abstrair cada vez 
mais, universalizar suas ideias, embora o discurso oficial não seja este. Este é o grande problema a ser destacado neste ensaio: a decisão aqui examinada embora afirme que analisará o caso com olhos voltados à práxis, o faz somente formalmente. Dizer, por exemplo, que não há confisco porque provavelmente a empresa irá repassar os custos aos usuários é alegar superficialmente uma das facetas dos problemas.

Embora, tenha sido uma decisão favorável a fruição de direitos fundamentais por parcela considerável da população brasileira, a decisão carece de uma fundamentação sólida. Utiliza conceitos desenvolvidos por vertentes contrapostas da filosofia política e do direito para examinar a questão, como será demonstrado. O escopo do artigo é justamente identificar na decisão judicial elementos da teoria kantiana e hegeliana. Para isso usará como referencial o legado da filosofia grega: a divisão entre o universalismo e o particularismo. O primeiro, tendo como precursor Platão e o segundo, Aristóteles.

Os direitos humanos previstos na Declaração dos Direitos das Pessoas Deficientes, assim como, na Resolução assinada na ONU e seu Protocolo facultativo regulamentam, de modo universal, a sua adoção e efetividade. Essa ideia de universalidade foi proposta inicialmente por Platão e acabou por influenciar vários teóricos, como Kant, que através de uma racionalização buscavam demonstrar como atingir a Ideia do Bem.

Denomina-se universal o paradigma que adota a Ideia do Bem como valor abstrato absoluto, logo, universal. Marginaliza-se o apego às divindades funcionais (aproximação da tradição, cultura locais e das experiências concretas), a respeito de um governante virtuoso que conduz a sociedade a uma vida estável e justa. Emergem, enfim, desta concepção dois elementos: a universalidade e o desapego as experiências práticas.

A controvérsia judicial concentrou-se, dentre outros elementos, na determinação do conteúdo do princípio da igualdade. Afirmou-se que esta norma jurídica não pode ter seu conteúdo preenchido com algo divino, mas sim direcionado ao conceito socialmente concebido de justiça. O ideário platônico, porém é abandonado com a tentativa de identificação da isonomia através de critérios práticos, ditados pela sociedade. ${ }^{3}$

Pocock (1975) usa o referencial do universalismo e do particularismo a partir de dados históricos para distinguir três modos de política. O primeiro é o modo tradicional: aqui se tem a utilização da prudência. É encontrado contemporaneamente aos processos dominados pelo costume tradicional, pelas divindades funcionais.

Ao segundo modo, Pocock (1975) denominou de atemporal: tem como referência o

\footnotetext{
${ }^{3}$ Nesta passagem também é identificada outra contradição do discurso oficial do Tribunal com a prática. A avaliação pormenorizada deste ponto será trabalhada posteriormente.
} vol.09, nº. 03, Rio de Janeiro, 2016. pp. 
universal que se encontra apartado do mundo sensível. Platão pode ser enquadrado neste modo. E, finalmente o modo cívico, pertencente ao período do humanismo italiano retomando o paradigma particularista, no qual enquadra-se Aristóteles.

Autores posteriores aos gregos clássicos, também procuraram na busca de identificar o Bem como fundamento do sistema político, avaliar os paradigmas particulares ou universais. Kant, embora influenciado pela teoria desenvolvida universalista de Platão, critica a metafísica especulativa até então utilizada. Mesmo com o objetivo de abandoná-la, acaba por desenvolvêla a partir de regras racionais, separadas do mundo sensível, preenchendo a falha teórica anterior a sua tese ${ }^{4}$. Formula a valorização de fundamentos abstratos à conduta humana, separados das contingências da vida e desenvolve "um exame 'crítico' da atividade da mente humana voltada para o distanciamento em relação aos eventos circunstanciais da vida" (CASTRO, 2005, p. 68).

Embora partam de uma mesma premissa, a universalidade, Kant critica o platonismo pela sua falta de rigor na busca da Ideia do Bem. Informa que a especulação existente em sua teoria acaba, ao contrário do almejado, aproximá-lo da vida prática, trazendo contradições internas. Faltava, segundo Kant, uma sustentação da livre manifestação do pensamento, a qual deveria ser fornecida pelo conjunto de conceitos a priori. É neste ponto que ele inicia sua trajetória de extermínio da metafísica especulativa com a introdução de um rigorismo científico. A partir de uma elaboração transcendental que, como tal, permitiria uma resposta universalizadora raciocina uma distinção do mundo idealizado e o mundo real. De um lado a liberdade moral e de outro as instituições coercitivas. No desenvolvimento de seu modelo, desenvolve, na "Fundamentação da Metafísica dos Costumes", a noção de Imperativos.

Há três formas de imperativos: os técnicos - responsáveis pela indicação de meios para fins escolhidos arbitrariamente; os hipotéticos - declaram a necessidade de uma ação para atingir um objetivo; e os categóricos - através dos quais se explica que uma ação é necessária em si mesma, ou seja, não constitui um meio para se atingir um fim qualquer.

O imperativo categórico ganha destaque nesta concepção, sendo necessário um exame dos pressupostos kantianos para o seu completo entendimento. Para Kant, as ações devem ser realizadas sem qualquer tipo de inclinação para que possuam conteúdo moral. A ação deverá acontecer por dever, independente da postura interna do sujeito, pois os motivos determinantes da realização da conduta são dados a priori e de maneira universal.

Dificilmente será possível identificar nos atos jurisdicionais, como é exemplo a decisão 
aqui analisada, a inexistência de inclinações, pois o sistema constitucional atual está baseado em valores socialmente admitidos para a realização do bem-comum. $\mathrm{Na}$ decisão discutida neste trabalho, é permanente a inserção de critérios axiológicos na definição do conteúdo das normas: o conceito de igualdade se dá com base na análise da diminuição da diferença, almejase pela solidariedade e fraternidade entre os indivíduos que compõem a sociedade. Resta claro, que não se deve cumprir a norma só por dever, mas também por inclinação, por fazer o bem ao indivíduo que não possui as mesmas condições. A hermenêutica constitucional contemporânea abriu um arcabouço de possibilidade do intérprete, inclusive, para inserir suas inclinações pessoais nos mais diversos julgamentos. O que aparentemente parece ser produtivo acaba, na prática, não passando de mero discurso vazio.

A inserção dos valores nas decisões judiciais ocorre de maneira abstrata e generalizadora. Tratam-se de valores jurídicos muitas vezes distanciados da sociedade e de suas contingências. Ou seja, percebe-se, nessa decisão, a reafirmação de uma matriz kantiana que entra em conflito com a nova tendência da hermenêutica constitucional brasileira.

Com isso, não se quer dizer que Kant acreditava que o sujeito não seria influenciado por suas inclinações, mas sim que a sua teoria buscou ao máximo racionalizá-las, como por exemplo, na análise a respeito da existência do amor, que deve acontecer, segundo Kant, por dever, sem qualquer tipo de inclinação subjetiva. Assim, mesmo que internamente o sujeito possua uma aversão a fazer o bem ou a amar ele o deverá fazer por dever.

O individualismo e o egoísmo, inclinações para Kant, e presentes na personalidade do sujeito também tendem a ser resolvidos com a razão. As contingências não podem domar o indivíduo fazendo com que este aja de acordo com suas vontades, mas sim, independente delas. Reitera-se: age-se por dever e não de acordo com o dever. A razão não se destina a satisfação das necessidades humanas, as quais seriam melhor atendidas pelo instinto natural inato, tampouco por uma faculdade prática; a razão deverá produzir uma boa vontade.

A vontade estimuladora da ação é a faculdade de escolher aquilo que a razão, independentemente das inclinações, reconhece com praticamente necessário. Assim, o conceito de dever integra-se ao da vontade, pois a ação só terá valor moral quando seu fim não for um objetivo pessoal a ser alcançado. Agir por dever significa agir de acordo com a lei, de base universal e levando em consideração a formulação de uma máxima.

Em suas palavras:

Conservar cada qual a sua vida é um dever, e é, além disso, uma coisa para

\footnotetext{
${ }^{4}$ Kant preenche este vazio com o desenvolvimento da estrutura do sujeito transcendental em três momentos expostos em suas obras: 10 - Crítica da razão pura (1781); 2o- Fundamentação da Metafísica dos Costumes (1785) e Crítica da razão prática (1788) e 3o- Crítica do juízo (1790).
} 
que toda gente tem inclinação imediata. Mas por isso mesmo é que o cuidado, por vezes ansioso, que a maioria dos homens lhe dedica não tem nenhum valor intrínseco e a máxima que o exprime nenhum conteúdo moral. Os homens conservam a sua vida conforme o dever, sem dúvida, mas não por dever. Em contraposição, quando as contrariedades e o desgosto sem esperança roubaram totalmente o gosto de viver, quando o infeliz, com fortaleza de alma, mais enfadado que desalentado ou abatido, deseja a morte, e conserva, contudo, a vida sem a amar, não por inclinação ou medo, mas por dever, então a sua máxima tem um conteúdo moral. (KANT, 2008, p. 25)

Portanto, na sua busca para demonstrar como é possível compreender o dever moral, Kant afirma que a felicidade não pode ser mensurada a partir de seu dever como obrigação de segui-la, mesmo que contrária a desejos internos, pois as inclinações dos homens não coincidem ou poderiam ser aceitas de maneira fortuita, não possuindo a característica da universalidade. Já os imperativos morais não permitem exceções. É através destes imperativos que Kant traz o rigor a sua teoria, afastando-a da metafísica especulativa. O imperativo considera a forma do dever como motivação de determinação do querer ético. (RÖD, 2008).

O imperativo categórico deverá obedecer a lei universal (apta a generalização) traduzida na seguinte fórmula: “ages como se a máxima da tua ação devesse se tornar, pela tua vontade, lei da natureza." (KANT, 2008, p. 52). Contrapor a máxima à regra de generalização serve para eliminar as que não podem ser consideradas morais, isto é, aquelas que se contradizem no processo de generalização.

Há uma forma estabelecida na busca da Ideia do Bem: a utilização dos imperativos exclui a especulação promovida pela metafísica pré-kantiana, mas por outro lado, não exclui a própria metafísica, pois a obrigatoriedade dos seres racionais em cumprir com as regras de generalização é dada a priori. Este é um dos impasses da vertente kantiana: tentar acabar com a metafísica, mas acabar retornando a ela como modo da fundamentação da lei universal.

Reitera-se por outro lado, a grande contribuição desta corrente: a formalidade trazida através da intenção kantiana de afastar qualquer análise subjetiva, qualquer tipo de inclinação ou contingência. A avaliação é objetiva, com preocupação apenas com o cumprimento da máxima moral, através de uma disciplina racional da mente humana através de critérios transcendentais distanciados da experiência humana ${ }^{5}$. Fala-se em contribuição, pois até Kant a metafísica era especulativa, sem qualquer tipo de racionalização.

Destaca-se ainda, outra formulação de imperativo categórico por Kant: "ages de tal maneira que possas usar a humanidade, tanto em tua pessoa como na pessoa de qualquer outro, sempre e simultaneamente como fim e nunca simplesmente como meio." (KANT, 2008, p. 59). Este imperativo ressalta o valor de ações que busquem a universalidade, baseadas na liberdade 
humana em relação ao empírico e na autonomia do sujeito que obedece as leis dadas por si mesmo (aplicação dos imperativos). A liberdade em Kant está no sujeito e não no mundo: o sujeito é livre na medida em que segue o dever criado por ele mesmo, enquanto sujeito universal. Liberdade é forma, desprovida de qualquer conteúdo concreto, atribuída a todos os seres racionais: "vontade livre e vontade submetida a leis morais são uma só e a mesma coisa". (KANT, 2008, p. 80).

\section{A ADI N. 2.649/DF E AS CONCEPÇÕES DE LIBERDADE}

O Supremo Tribunal Federal (2008, p. 47, grifo nosso) ao analisar a concessão ou não do passe-livre para os deficientes avaliou o significado de liberdade, a partir da livre-iniciativa, e assim se manifestou:

[...] o empresário que constitui uma empresa voltada à prestação de serviço público de transporte coletivo ampara-se no princípio constitucional da livre iniciativa para constituir sua empresa, não dispõe de ampla liberdade para a prestação daquele serviço. Porque ele é concessionário ou permissionário de um serviço público. E quanto a esse nem ao menos o Poder Público tem liberdade. Presta-o porque tem de, não porque assim quer ou decide. A decisão sobre esse serviço, a sua qualidade de serviço público está na Constituição [...]

Segundo a concepção kantiana o pressuposto da liberdade é a autonomia da vontade. Esta existirá quando o sujeito não se deixar levar pelo mundo sensível, mas, ao contrário, quando possuir força suficiente para agir independente deste. Ou seja, a liberdade é possibilidade do sujeito de livrar-se das inclinações e contingências do mundo sensível.

No destaque do trecho da decisão acima transcrita resta evidente um traço da concepção kantiana no exercício da liberdade. O empresário, no caso, não é livre, pois age de acordo com sua inclinação (neste caso, a não concessão do passe-livre) e não por dever a uma ordem. Do mesmo modo, o Tribunal destaca como relevante a postura de liberdade através da ação moral dadas a priori e não por questões pessoais. Este tipo de liberdade, todavia, reflete uma concepção de liberdade meramente formal, sem conteúdo, enfim uma liberdade vazia.

Ao contrário de Kant, Hegel não fundamenta a liberdade na forma (no vazio). Não o faz, porque acredita que esta concepção gera o fanatismo e a destruição de toda a ordem tanto no aspecto religioso (exemplificando a partir do fanatismo da contemplação hindu) quanto no aspecto político, com o aniquilamento de qualquer ordem. Assim, a ordem é sempre a restrição da liberdade (HEGEL, 2000).

A concepção hegeliana de liberdade parte da insustentável separação kantiana entre

\footnotetext{
${ }^{5}$ Neste sentido, os utilitaristas não aderem a teoria kantiana, uma vez que buscam a finalidade da lei, dos institutos com base em critérios contingenciais.
} vol.09, n. 03, Rio de Janeiro, 2016. pp. 
política e moral, entre o mundo sensível e o da razão para concluir que o mundo real se apresenta como um mundo conformado ao espírito, ou seja, "conformado à autoconsciência da liberdade humana ou da razão", devendo a "filosofia estar a serviço do Estado na determinação da consciência ética do bem comum, e que as leis racionais (ou direito racional) seriam a sua expressão". Busca, assim, uma conciliação entre a liberdade radical kantiana e da união entre o indivíduo, sociedade e a natureza (CASTRO, 2005, p. 80).

Surge, neste contexto, o famoso aforisma hegeliano "o que é racional é real e o que é real é racional" (HEGEL, 2000, p. XXII), demonstrando que a racionalidade é construída a partir da realidade. Para ele, a Ideia do Bem (ideal a ser atingido por Platão) forma a consciência humana que está incompleta. Buscar a unidade compreensível desta consciência através da experiência é o objetivo hegeliano. Parte de algo contingente e inacabado: o ser, para atingir a Ideia, completa e universal.

Esta oposição ao pensamento kantiano remonta a concepção trazida pelo outro paradigma da filosofia grega: o do particularismo, almejado por Aristóteles. A concepção particularista aristotélica leva em consideração a pluralidade e diversidade como algo intrínseco a existência do Estado. Esta miscelânea plural conduz ao desenvolvimento de facções que, por possuírem objetivos particulares, podem gerar conflituosidade. Para combatela, Aristóteles, impõe a importância dos meios institucionais.

Aristóteles percebe a sociedade limitada por hierarquias naturais que são imutáveis, sendo que no centro da sociedade estaria a família e a virtude estaria na escolha de um meiotermo, no uso da moderação como requisito de uma ordem social justa. Desperta Aristóteles para a ampliação de valores cívicos. A pluralidade de ideias e o particularismo caracterizam o modo cívico (vivere civile) proposta por Pocock (1975). Essa concepção de sociedade e de política atingiu o humanismo italiano que pugnou pela interação social. (POCOCK, 1975).

A partir da demonstração de seus pensamentos principalmente na tese de que através de experiências particulares e de uma consciência incompleta pode-se alcançar uma unidade intelegível (descrita primordialmente em sua obra "Princípios da filosofia do Direito"), é possível enquadrar Hegel no paradigma particularista.

A oposição a teoria kantiana é decorrência também da proposição de separação da moral com a política. Conforme assinalado, Kant deixava a inclinações no campo da política mas a excluía da moral. Hegel, aproxima os dois conceitos afirmando que a moral é subjetiva, mas também objetiva (exterior). Entende que os sujeitos, na sociedade moderna, não possuem plena consciência do todo, mas acabam por juntar-se a determinados grupos, com interesses próprios e muitas vezes opostos aos dos sujeitos. Para que se realize o bem de todos faz-se vol.09, n. 03, Rio de Janeiro, 2016. pp. 
necessário um princípio diretivo que para Hegel é o Estado, ou seja, há uma contraposição entre sociedade civil e instituições cabendo a estas a realização ética do bem e barrar a desagregação social (CASTRO, 2005).

Hegel busca nas instituições a fundamentação da realização ética pois o indivíduo na sociedade moderna não é capaz de adquirir naturalmente a consciência do bem, como propugnava Kant (lembrar-se que para este a aquisição da consciência do bem ocorreria através das leis transcendentais da liberdade moral expressas nos imperativos categóricos). $\mathrm{O}$ individuo por causa das relações comerciais e da complexidade da sociedade, segundo Hegel, é incapaz de individualmente atingir este objetivo.

Assim, Hegel impõe como função das instituições a prevenção da desagregação social e a determinação da realização da consciência ética do bem comum aproximando-se de Aristóteles e, consequentemente, do paradigma particularista, ao perceber a interação social é concebida a partir de associações primárias como a família.

Avaliar a transformação das associações conduz a um ponto central na teoria hegeliana: a importância dada a história como um processo, no qual se deve sempre buscar a moderação, o meio-termo, é aí que se encontra a virtude. ${ }^{6} \mathrm{E}$ se a história ocupa lugar central em sua teoria, a noção de justiça para ele não está separada da prática, da experiência. A moral é exterior e objetiva e não interna, por isso para Hegel a sociedade está reunida em grupos coordenados pelo Estado que procura desenvolver o bem para todos, já que muitas vezes os indivíduos não possuem plena consciência que seus atos constituem um caminho ao bem.

$\mathrm{Na}$ controvérsia posta a resolução pelo Judiciário e analisada no artigo, verifica-se que é possível identificar uma busca discursiva de elementos hegelianos de construção de uma consciência ética. A Ministra relatora ao descrever a importância de serem assegurados direitos a pessoas com deficiências, examina o contexto social informando que, segundo a ONU, aproximadamente $10 \%$ da população mundial possui algum tipo de deficiência, sendo que a maior parte destas pessoas ( 8 em cada 10) concentram-se em países em desenvolvimento. Parte, portanto, do ser para construir sua teoria.

$\mathrm{Na}$ ausência de uma aquisição natural da Ideia do Bem, o Estado através de suas instituições busca conduzir os grupos (ou facções na expressão aristotélica) ao seu alcance, foi o que ocorreu com a introdução de medidas para inserir na sociedade o grupo das pessoas portadoras de deficiência. Note-se que a naturalidade querida por Kant é impossível, tanto que, mesmo o Estado direcionando os grupos a aquisição da Ideia do Bem, estes se debatem e utilizam as instituições para tentar não cumprir com este princípio buscando interesses 
pessoais.

Essa contradição existente nas diversas "facções" ou grupos que compõem a sociedade atual é perceptível inclusive nas instituições. Põe-se, assim, uma controvérsia deste tipo na decisão aqui trazida: o discurso usado pelo Judiciário brasileiro é incompatível com suas decisões. Isto significa que ao disciplinar o conteúdo do princípio da igualdade como algo composto pelo ideal de justiça, que por sua vez, deveria ser construído empiricamente pela sociedade, o Judiciário deveria buscar de maneira interdisciplinar os elementos que compõem esse arcabouço. Mas não, analisa dados singulares, a partir de um viés jurídico abstrato e generalizador, desprezando elementos empíricos na análise do caso concreto, aproximando-se muito mais da vertente kantiana do que da hegeliana.

\section{UMA POSSÍVEL CONTRIBUIÇÃO DA PROPORCIONALIDADE AO DEBATE CENTRAL DA ADI N. 2.649/DF}

A busca pela moderação hegeliana, o meio-termo como virtude, assim como a liberdade como possibilidade do sujeito de livrar-se das inclinações e contingências do mundo sensível, embora identificáveis na decisão e associadas a alguma forma de tentativa de correição nas escolhas, não fundamentam a aplicação adequada da proporcionalidade como máxima na solução de problemas de colisão de princípios. A decisão deparou-se ao menos com dois princípios, o primeiro que protege a propriedade e o segundo que protege a igualdade.

Para fundamentar a observação sobre esse encontro (em eventual colisão) é importante identificar em que medida se compreende princípios e orienta-se a aplicação da proporcionalidade, pois tais entendimentos estarão diretamente associados à ponderação.

No entender de Alexy (1988, p. 149-150) a racionalidade na fundamentação jurídica sempre encontrou dificuldades por raciocínios muito extremos. De um lado, variantes subjetivistas, relativistas, decisionistas ou irracionalistas, e, de outro, objetivistas, absolutistas, cognocistivistas ou racionalistas, mas sempre na lógica do "tudo-ou-nada". Afirma ainda que não são possíveis teorias morais materiais que, para cada questão prática, permitam extrair uma resposta, mas são possíveis teorias morais procedimentais que formulem regras ou condições de argumentação para uma decisão prática racional. Assim, com um sistema de regras e princípios do discurso (propõe um conjunto de 28 regras), será assegurada a racionalidade da argumentação e de seu resultado.

\footnotetext{
${ }^{6}$ A liberdade é um processo histórico também.
} vol.09, n. 03, Rio de Janeiro, 2016. pp. 
Consequentemente, numa espécie de codificação de posturas, a razão prática pode ser complementada com regras específicas do discurso jurídico. Nisso está a base para a justificação ou crítica das decisões e do sistema jurídico em seu conjunto (ALEXY, 1988, p. $150)$.

Esse estabelecimento procedimental visa garantir uma resposta ao problema sério do casuísmo nas decisões judiciais, algo grave que afeta o aspecto de correção a que o Direito não positivista deve estar conectado.

Essa ótica de correção é ilustrada por Alexy (2011, p. 6-7) com o exemplo do "injusto legal - não direito" da decisão sobre cidadania do Tribunal Constitucional Federal. Nessa decisão, o Tribunal considerou uma lei racista alemã, que privava da nacionalidade alemã os judeus emigrados, uma lei nula $a b$ initio. Tal decisão foi estabelecida em uma demanda individual (havia elementos para demonstrar tanto a legalidade, quanto a eficácia social para outros indivíduos), mas o Tribunal optou por considerar a nulidade total e ab initio da lei, sob o fundamento de que: "O direito e a justiça não estão à disposição do legislador. [...] o Tribunal Constitucional Federal afirmou a possibilidade de negar aos dispositivos 'jurídicos' nacionalsocialistas sua validade como direito." Para o Tribunal "[...] uma vez que eles contrariam os princípios fundamentais da justiça, de maneira tão evidente que o juiz que pretendesse aplicálos ou reconhecer seus efeitos estaria pronunciando a injustiça, e não o direito (BVerfGE 3, 58 (119); 6, 132 (198)).

Alexy (2007, p. 28) estrutura seu pensamento a partir da constatação de como podem ser necessárias valorações, isto é, julgamentos de qual alternativa pode ser eleita como a melhor em algum sentido, como ocorre a relação dessas com os métodos de interpretação jurídica, com os enunciados e conceitos da dogmática jurídica, e, finalmente, como elas podem ser racionalmente fundamentadas e justificadas.

Segundo Alexy (2007, p. 33), enfrentando algumas dificuldades postas a sua tese, seria também um erro deduzir que há um campo livre, no processo valorativo, para convicções morais dos aplicadores do Direito. As tentativas de buscar a forma de objetivação para a valoração são por ele agrupadas nas seguintes posturas ${ }^{7}$ :

(1) basear-se em convicções e consensos faticamente existentes, assim com em normas não jurídicas faticamente vigentes ou seguidas; (2) referir-se a valorações que, de alguma maneira, podem ser extraídas do material jurídico existente (incluídas as decisões anteriores) e (3) recorrer a princípios

\footnotetext{
7 (1) basarse en convicciones y consensos fácticamente existentes, así como en normas no jurídicas fácticamente vigentes o seguidas; (2) referirse a valoraciones que, de alguna manera, pueden ser extraídas del material jurídico existente (incluidas las decisiones anteriores) y (3) recurrir a principios suprapositivos. [...] (4) apelar a conocimientos empíricos ${ }^{7}$ [excepto los presupuestos en (1)]. (ALEXY, 2007. p.33). Tradução nossa.
} vol.09, n. 03, Rio de Janeiro, 2016. pp. 
suprapositivos. [...] (4) apelar a conhecimentos empíricos ${ }^{8}$ [exceto os pressupostos em (1)].

Alexy (2007, p. 33) entende a insuficiência das condutas realizadas nas tentativas de objetivação, argumentando que, nas sociedades, há diferentes concepções para quase a totalidade de problemas práticos, assim como, os consensos práticos são raros. Considera que o amparo buscado na evidência e na ordem natural preexistente é extremamente duvidoso; assim como os juízos fáticos podem resultar em diferentes consequências normativas.

Para o problema das valorações, vê na argumentação jurídica, como atividade linguística, a possibilidade de busca de correção. Para ele, "Será conveniente designar tal atividade como 'discurso', e, por se tratar da correção de enunciados normativos, como 'discurso prático'. O discurso jurídico é um caso especial do discurso prático geral". 9

Ao buscar desenvolver uma teoria analítico-normativa do discurso jurídico, Alexy (2007, p. 35) estabelece como ponto central a ideia de que o discurso jurídico é um caso especial do discurso prático geral e como tal, face a finitude de argumentos jurídicos, haverá na base discursiva a identificação de argumentos morais e a necessária exigência de justificação.

A sua teoria geral do discurso prático racional tem como núcleo cinco grupos que totalizam vinte e duas regras, assim como uma tábua de seis formas de argumentos, cujo objetivo principal é fazer aparecer mais claramente os defeitos sobre o conteúdo de uma regra, a incompletude de sua enumeração, o caráter supérfluo de algumas regras como também a imprecisão de sua formulação (ALEXY, 2007, p. 36). Isso também será fundamental para o exame de direitos fundamentais, no momento da definição das condições de precedência para a ponderação.

Alexy (1988) já entendia uma correspondência entre princípios e valores. Haveria uma correspondência entre problemas de prioridade de princípios e hierarquia de valores, que se distinguem por um exame de planos: deontológico (para princípios) e axiológico (para valores). Seguiu, então, para suas teses, realizando uma atividade analítico-conceitual do sistema normativo.

As normas se diferenciam em termos estruturais. Importante distinção nesse âmbito interpretativo deve ser feita entre regras e princípios ${ }^{10}$; que permite uma resposta mais

\footnotetext{
${ }^{8}$ Segundo Alexy: Tales conocimientos empíricos son de gran importancia en las fundamentaciones jurídicas, pero sólo de ellos no se pueden deducir premisas normativas.

9 "Será conveniente designar tal actividad como 'discurso', y, puesto que se trata de la corrección de enunciados normativos, como 'discurso práctico'. El discurso jurídico ${ }^{9}$ es un caso especial del discurso práctico general.” (ALEXY, 2007. p.34). Tradução nossa.

${ }^{10}$ Não é objetivo do presente texto apresentar a distinção entre regras e princípios. Reserva-se o espaço principal para uma compreensão mais apurada dos princípios, posto que sua análise é mais intima da ponderação. No entanto, Aguiló Regla apresenta uma série de tópicos, pelos quais os pontos de convergência e divergência entre os paradigmas do positivismo e pós-positivismo podem ser destacados e de início vol.09, $\mathrm{n}^{\circ}$. 03, Rio de Janeiro, 2016. pp. 1466
} 
adequada às demandas de concretização dos direitos fundamentais, como na decisão do STF, dentro de parâmetros de racionalidade.

A base da teoria dos princípios é a distinção entre os tipos normativos regras e princípios (ALEXY, 2014, p. 52). Diretamente, Alexy (2014, p. 52) define regra como “[...] norms that require something definitively. They are definitive commands. Their form of application are fulfilled, it is definitively required that exactly what it demands be done." Princípios como mandamentos de otimização "[...] each taken alone, always comprise a merely prima facie requirement. The determination of the appropriate degree of satisfaction of one principle relative to the requirements of the other principles is brought about by balancing."

Para Alexy, o ponto central distintivo entre os dois modelos normativos é que "[...] princípios são normas que ordenam que algo seja realizado na maior medida possível dentro das possibilidades jurídicas e fáticas existentes.” Princípios são por ele qualificados como mandamentos de otimização e têm como característica a possibilidade de satisfação em graus

apresenta dois modelos: o modelo de regras, elemento marcante do positivismo e o modelo de regras e princípios do pós positivismo. No primeiro, o modelo de regras é apresentado como adequado ao sistema jurídico positivista. Para tanto, o ideal regulativo é o da tipicidade, cuja valoração é feita por ocasião da criação da regra e não da sua utilização. Para o citado autor, as normas devem ser precisas, diretas e fechadas. As normas abertas ocorrem por imprecisão da técnica legislativa ou, em última análise, como hipóteses de delegação legislativa. Tal modelo foi erguido pelos ideais da previsibilidade e da certeza. Por outro lado, no paradigma pós positivista, embora considerem-se as regras necessárias, tal modelo puro de regras é insuficiente. Para a constituição do conceito integral de norma, é fundamental a inclusão de princípios, ou seja, o modelo é o de regras e princípios. Os princípios, ao contrário das regras, conforme explica Atienza, trazem razões não peremptórias, isto é, dão uma razão para um determinado comportamento, mas não afastam outras possíveis razões, impondo ao caso concreto uma prática deliberativa, um processo de ponderação para verificação da força dessas razões e solução incidental. A importância dos princípios nesse modelo normativo é tamanha que se tornam, inclusive, vetores de criação e valoração das próprias regras, dando o seu sentido de coerência material. Em relação ao modelo das relações lógicas entre normas e ao modelo de relações lógicas e relações de justificação, Aguiló expõe que, no positivismo, entre as regras de um sistema se dá uma lógica de dedutibilidade e eventuais e indesejáveis conflitos de normas se resolvem pela prevalência de uma sobre as demais, por critérios definidos baseados na hierarquia, posterioridade e especialidade. Já no pós-positivismo, prega-se uma relação de coerência valorativa para o conjunto normativo, isto é, para regras e princípios. Para as regras há ainda um processo de solução de conflitos baseado na hierarquia, posterioridade e especialidade. No entanto, quanto às normas-princípio, distante da posição positivista do "tudo ou nada", há a coexistência de normas, que no caso concreto deverão triunfar, sem se dizer que em outro caso concreto não poderá triunfar a norma contrária, isto é, incidirão com critérios de ponderação. Esses raciocínios estão desenvolvidos em: AGUILO REGLA, Josep. Sobre Derecho y Argumentación. In Sobre Derecho y Argumentación. Palma (Mallorca): Lleonard Muntaner, 2008, p. 11-28. e ROESLER, Cláudia R. Direito e Argumentação no Pensamento de Manuel Atienza. 2007. p. 44. Também é importante destacar, como explica Pietro Sanchís: “[...] desde el positivismo, en efecto, se ha mantenido tanto la tesis de la unidad de respuesta correcta (el llamado paleopositivismo), como la tesis de la discrecionalidad (kelsen, Hart); y desde el constitucionalismo, o asumiendo las consecuencias del mismo, resulta posible encontrar tambien defensores de la unidad de solución correcta (Dworkin), de la discrecionalidad débil (Alexy) y de la discrecionalidad fuerte (Guastini, Comanducci)" (PIETRO SANCHÍS, 2005. p. 135). Para Figueroa, a Teoria de Alexy concebe os princípios como mandados de otimização, no sentido de indicar ao juiz que a norma deve ser aplicada na maior medida possível, dentro das possibilidades jurídicas e fáticas. (FIGUEROA, 2005. p. 179). 
variados, e pelo fato de que a medida devida de sua satisfação não depende somente das possibilidades fáticas, mas também das possibilidades jurídicas. $\mathrm{O}$ âmbito das possibilidades jurídicas é determinado pelos princípios e regras colidentes. (ALEXY, 2015, p. 90)

A construção teórica para a ponderação observa que, com grande frequência, o caráter principiológico das normas, especialmente as de direitos fundamentais é manifestado, até mesmo de forma referencial, quando se fala em valores, objetivos ou regras sobre distribuição de algum ônus argumentativo (ALEXY, 2006 p. 86). Contudo, Alexy não nega - muito pelo contrário - a existência de regras, inclusive sob o ponto de vista da análise estrita de direitos fundamentais, em que há espaço inclusive para uma direta aplicação de um raciocínio dedutivo. Para a proposta de Alexy, tanto princípios quanto regras são normas e dizem o que deve ser. Ambas são expressões básicas do dever, da permissão e da proibição. (ALEXY, 2006, p. 87)

Ainda no âmbito de seleção das possibilidades jurídicas, a colisão de princípios impõe um raciocínio completamente diverso. Um primeiro âmbito de análise indica que, na colisão, o princípio que não prepondere não sofrerá nenhum tipo de juízo de invalidez, restrição geral ou incompatibilidade com o conjunto normativo (nenhuma forma, nesse sentido, de solução universalista ou de (in)aplicabilidade a priori). Haverá apenas uma construção de precedência, condicionada a determinadas situações, de um principio sobre outro. (ALEXY, 2006, p. 93)

Alexy raciocina que a relação de precedência entre um princípio e outro é determinada pelo peso ${ }^{11}$ de cada princípio. Então, se nas regras, o procedimento é a verificação da validade, nos princípios, o procedimento está na dimensão do peso, que não se opera no plano abstrato, mas revela importantes resultados no plano concreto. Pode haver quatro distintas situações quando se trata de princípios colidentes: o princípio 1 incondicionalmente prepondera ao princípio 2; o princípio 2 incondicionalmente prepondera ao princípio 1. São essas relações de precedência abstrata. No entanto, podem existir uma terceira e uma quarta possibilidades: o princípio 1 sob determinada condição, prepondera ao princípio 2 e o princípio 2, sob determinada condição, prepondera sob o princípio 1. Tratam, as duas últimas hipóteses, de uma preponderância concreta. Assim, sempre tendo em consideração o caso concreto, constrói-se a relação de precedência fixando-se em que condições um princípio precederia a outro. Trata-se, portanto, da compreensão de um modelo de precedências condicionadas (ALEXY, 2006, p.96).

\footnotetext{
${ }^{11}$ Alexy (2015, p. 594) explica como se faz o sopesamento. Ele é dividido em três etapas: na primeira etapa, é avaliado o grau de afetação ou de não satisfação de um dos princípios. No passo seguinte, avalia-se a relevância de satisfação do princípio colidente. No terceiro passo, deve avalia-se se a satisfação do princípio justifica a afetação do outro.
} vol.09, n. 03, Rio de Janeiro, 2016. pp. 
Para essa compreensão, Alexy utiliza a metáfora do peso ${ }^{12}$. Os interesses que originaram a colisão concreta de princípios são identificados e tratados com pesos. Trata-se a aplicação do sopesamento segundo Alexy, não de um método matemático, mas de uma formulação de racionalidade, posto que, num caso concreto, levaria a regras para o raciocínio, por exemplo: "se uma ação preenche as Condições ' $C$ ', então ela feriria um direito fundamental e seria proibida". Dessa forma, de um enunciado de preferência sobre uma relação condicionada de preferência decorreria uma regra. Tal regra, presente a condição de preferência, prescreveria uma consequência jurídica do princípio prevalente. Nas palavras de Alexy, "As condições sob as quais um princípio tem precedência em face de outro constituem o suporte fático de uma regra que expressa a consequência jurídica do princípio que tem precedência." (ALEXY, 2006, p. 99)

A lei acima, chamada por Alexy lei de colisão, é um dos fundamentos da teoria dos princípios. Tal teoria, em bases compatíveis e convergentes com uma teoria de direitos fundamentais, pode apresentar como resultados do sopesamento normas de direito fundamental atribuídas.

Partindo da lei de colisão e do sopesamento, na construção de um modelo de análise de decisões judiciais, podem-se indicar três etapas. A primeira delas consistiria na identificação

12 “[...] a lei de ponderação mostra que o processo de pesagem pode ser dividido em três estágios: 1. definição do grau de interferência em um dos princípios; 2. definição da importância da satisfação do princípio que atua em sentido contrário; e 3. verificar se a importância do princípio contrário justifica ou não a afetação do primeiro princípio." (BUSTAMANTE, 2008, P. 259).

Haverá a realização de um quociente para pesagem, aplicado pela intensidade de intervenção em um princípio, de um lado e a importância de satisfação do princípio colidente de outro. Isso indicará, o peso relativo dos princípios envolvidos. Como quociente haverá, aplicando-se o modelo triádico de Alexy, 9 resultados distintos, 3 prevalecendo um princípio, 3 prevalecendo o outro e 3 situações de impasse, nas quais está a margem de ação do produtor da norma. Alexy (2006), dentro das situações de impasse identifica uma margem de ação. Margem de ação estrutural estaria em situações em que a satisfação de um princípio ou a restrição do princípio colidente seriam igualmente autorizadas pela Constituição. A margem de ação epistêmica decorre da incapacidade de conhecer os limites constitucionais. Pode ser oriunda dos limites do conhecimento empírico ou de limites do conhecimento normativo. Feitas essas distinções Alexy apresentou um modelo duplo triádico para auxiliar as situações de impasse em margens estrutural ou epistêmica pelos limites do conhecimento normativo. Para a margem epistêmica por limites do conhecimento empírico Alexy sugere uma segunda lei da ponderação, que tem como divisor e dividendo a intensidade de intervenção e o grau de certeza das premissas.

Bustamante (2008, p. 289) busca contribuir com o modelo teórico proposto por Alexy no que diz respeito a determinação do peso abstrato dos princípios jurídicos, buscando estabelecer uma escala para a determinação desses pesos, classificando os princípios em geral e estabelecendo critérios de enquadramento dos princípios nessa classificação. Isso permitiria o estabelecimento de ordens de prioridade prima facie o que considera distinto de uma hierarquização pura e simples. Para tanto propõe uma classificação de três níveis: princípios de restringibilidade excepcional, de restringibilidade ocasional e de restringibilidade ordinária. Reconhecendo que qualquer pretensão de classificação de princípios não poderia buscar traços de exaustividade, Bustamante apresenta critérios móveis: 1) critério da importância para coerência do sistema; 2) critério de ligação com direitos individuais; 3) precedência prima facie da liberdade e igualdade. Assim "Para determinar o peso abstrato dos princípios, e, assim, para classificar os princípios jurídicos quanto ao vol.09, n. 03, Rio de Janeiro, 2016. pp. 
dos princípios contraditórios ou valores constitucionais em rota de colisão no caso concreto em questão. Em uma segunda etapa, estariam as identificações das configurações típicas do caso e as condições de precedência, isto é, nas observações em que um ou outro princípio teria precedência. Essa etapa é, provavelmente, a mais sensível no sopesamento, pois a identificação das condições de precedência não pode ser feita através de simples opiniões, mas deve corresponder a um resultado submetido às regras e formas apresentadas pela teoria da Argumentação Jurídica.

$\mathrm{Na}$ terceira etapa, a identificação das escolhas das condições de maior peso, que importaram no resultado decisório. Dessa forma, numa eventual avaliação, seria possível identificar o grau de coerência entre as etapas e os possíveis níveis de justificação das opções decisórias. Para isso, também é importante compreender o significado de proporcionalidade.

Ao falar sobre os direitos constitucionais e a possível relação com a análise de proporcionalidade, Alexy (2014) afirma ser possível duas teses, as quais tratam essa relação como "necessária" ou "contingencial" e filia-se à primeira, na qual a legitimidade da análise da proporcionalidade é uma questão da natureza dos direitos constitucionais. Para ele, em colisões de princípios, haverá a aplicação da proporcionalidade, que em sua dimensão fática demandará o sopesamento ${ }^{13} \mathrm{e}$ "The Law of Balancing is to be found, in different formulations, nearly everywhere in constitutional adjudication”" (Alexy, 2014, p. 54).

Alexy (2014, p. 57-59) entende que há uma indissociável/necessária relação entre princípios, como mandamentos de otimização e a proporcionalidade, chamada por ele de Primeira Tese da Necessidade. Aponta e rebate duas objeções feitas a essa tese. A primeira que o mandamento de otimização, que demanda a aplicação no "máximo possível" não seria na realidade um problema de sopesamento, mas de correção (dependente de uma argumentação moral específica). Alexy replica dizendo que, tanto o conceito de moralidade quanto o de correção, requerem o sopesamento quando há interferência com um direito constitucional. A correção de uma interferência dependerá da demonstração dessa intervenção poder ser justificada. Em casos de inadequação ou desnecessidade dessa intervenção, não haverá razões para essa intervenção e ela não será justificada. Passados esses testes, a correção ainda passará

grau de restringibilidade, é preciso combinar os critérios [...]. Depois de determinado esse peso abstrato, a fórmula de ponderação resolve o problema."

${ }^{13} \mathrm{Na}$ realização de críticas a teoria dos princípios, um grupo delas afirma que a teoria acaba presa em um círculo vicioso por pretender demonstrar antecipadamente aquilo que só pode ser demonstrado finalmente, isto é, que a teoria buscaria distinguir regras e princípios pelo seu modo de aplicação. Bustamante (2008, p. 265) já esclarece que, na realidade, não se trata propriamente de diferenças do modo de aplicação fazer as diferenças entre os tipos normativos, mas a consequência das diferenças entre regras e princípios impor modos de aplicação que se distinguem. O caráter de mandamento de otimização, algo como um dever-ser 
pela proporcionalidade em sentido estrito. Alexy ainda esclarece que argumentos morais são indispensáveis para a fórmula do peso. Porém, deve se ter em mente que a fórmula do peso não é uma alternativa para o argumento moral, mas um elemento estrutural para a argumentação (Direito e Moral) discursiva ${ }^{14}$.

Sobre a ligação da proporcionalidade e os direitos constitucionais, Alexy $(2014$, p. 60) identifica críticas no sentido de que a teoria dos princípios não seria uma teoria universal dos direitos fundamentais. Só haveria algumas "ilhas de mandados de otimização" no campo dos direitos constitucionais, pois dependeria a proporcionalidade de expressas concessões do direito constitucional positivo. Alexy entende que ver os direitos constitucionais como um direito positivado não explica a natureza de tais direitos. Existem outras dimensões a serem analisadas.

Para Alexy (2014, p. 61), direitos humanos podem ser qualificados como morais, universais, fundamentais, abstratos e têm prioridade sobre outras normas. Disso, numa análise inicial, deriva um discurso de validade moral, que depende da possibilidade de justificabilidade, que se procede em termos fornecidos por uma teoria do discurso. Pelo teor dos direitos, especialmente os fundamentais abstratamente caracterizados, também não é difícil perceber a grande quantidade de inevitáveis colisões e, portanto, devem ser concretamente sopesados. Assim, percebe-se a conexão necessária entre princípios, proporcionalidade, sopesamento, correção, justificação e racionalidade, elementos fundamentais da teoria alexyana.

ideal (nas palavras de Bustamante) e formulações de determinações comportamentais (regras) levam a modos de aplicação distintos.

${ }^{14}$ Bustamante (2008, p. 270) afirmou que “[...] é necessário retornar à vinculação necessariamente existente entre o modelo de ponderação proposto por Alexy e a teoria da argumentação jurídica. Sem esta última, seria impensável realizar a tarefa de fundamentação dos enunciados de preferencia condicionada que se estabelecem diante de cada colisão de direitos."

Assim, uma decisão racionalmente fundamentada passará pelo atendimento da exigência da argumentação na aplicação das regras e princípios envolvidos. Uma decisão que envolva princípios e, por conseguinte, requisite a ponderação demandará um acréscimo em sua argumentação. Bustamante (2008, p. 273) faz referência a este tipo de argumentação jusfundamental, na qual além das regras e condições ordinária a máxima da proporcionalidade ocupa um papel central na atribuição de racionalidade.

Bustamante (2008,p. 274), nesse sentido, afirmou que a máxima da proporcionalidade, com atribuição metodológica, é uma estrutura complexa de raciocínio decorrente da ideia de otimização e é subdividida em três regras: 1) regra da adequação, se o meio escolhido é hábil a fomentar o fim pretendido pelo princípio; 2) regra da necessidade, pois havendo dois meios de fomentar o princípio fim deve ser escolhido o meio que menos afete o princípio colidente e 3) regra da proporcionalidade em sentido estrito, no âmbito de relativização dos princípios frente as possibilidades normativas.

Bustamante (2008, p. 275) faz uma observação importante sobre a proporcionalidade: “[...] não é um parâmetro material para a argumentação jurídica. Ao contrário, trata-se de uma estrutura formal de aplicação dos princípios constitucionais. A proporcionalidade só permite controlar a restrição e a otimização de princípios depois que o intérprete tenha atribuído os pesos específicos aos princípios colidentes; se houver dúvidas acerca do "grau de interferência" ou da "importância das razões para a interferência" em um direito fundamental, são necessários argumentos exteriores a ela."

vol.09, n. 03, Rio de Janeiro, 2016. pp. 
Partindo-se dessas premissas, é possível identificar na decisão a presença de uma colisão de princípios, que não autorizariam, a princípio, o estabelecimento de prioridades abstratas, posto que assim estariam suprimindo elementos essenciais da máxima e comprometendo a pretensão de correição.

Logo, ante o que aqui de expôs, percebe-se que a resolução do litígio aqui rememorado, ao menos pelo que indica seu relato, demandaria uma melhor aplicação dos elementos do sopesamento. E isso, certamente, não se pode estabelecer a priori (ao menos para casos não superlativos).

\section{CONSIDERAÇÕES FINAIS}

Conforme relatado, a decisão escolhida e rememorada para o presente artigo é muito rica. Retrata como ponto central a definição do conteúdo do princípio da igualdade como base da possibilidade do Estado intervir na propriedade privada e na atuação comercial de empresas, inclusive o fazendo de maneira abstrata e a priori. Afasta, consequentemente, também abstratamente a liberdade dos contratos e das regras da livre iniciativa na tentativa de garantir maior estabilidade social, encaminhando os interesses que emanam dos diferentes grupos sociais sob o fundamento de se atingir "Ideia do Bem".

A partir das possibilidades trazidas pelos argumentos da decisão, o escopo do artigo foi identificar elementos da teoria kantiana e hegeliana. Para isso fez uso de um exercício já ligado a figuras legadas pela filosofia grega: a divisão entre o universalismo e o particularismo. $\mathrm{O}$ primeiro, tendo como precursor Platão e o segundo, Aristóteles, acabando por influenciar vários teóricos, como Kant e Hegel.

Denominou-se universal o paradigma que adota a Ideia do Bem como valor abstrato absoluto, logo, universal. Marginaliza-se o apego às divindades funcionais (aproximação da tradição, cultura locais e das experiências concretas), a respeito de um governante virtuoso que conduz a sociedade a uma vida estável e justa. Emergem, enfim, desta concepção dois elementos: a universalidade e o desapego as experiências práticas.

Percebeu-se que a controvérsia judicial concentrou-se, dentre outros elementos, na determinação do conteúdo do princípio da igualdade. Afirmou-se que esta norma jurídica não pode ter seu conteúdo preenchido com algo divino, mas sim direcionado ao conceito socialmente concebido de justiça. O ideário platônico, porém é abandonado com a tentativa de identificação da isonomia através de critérios práticos, ditados pela sociedade.

O Supremo Tribunal Federal ao analisar a concessão ou não do passe-livre para os deficientes avaliou o significado de liberdade, a partir da livre-iniciativa, muito próximo a 11501172 vol.09, nº. 03, Rio de Janeiro, 2016. pp. 
concepção kantiana que o pressuposto da liberdade é a autonomia da vontade. Esta existirá quando o sujeito não se deixar levar pelo mundo sensível, mas, ao contrário, quando possuir força suficiente para agir independente deste. Ou seja, a liberdade é possibilidade do sujeito de livrar-se das inclinações e contingências do mundo sensível. O empresário não seria livre, pois agiria de acordo com sua inclinação (neste caso, a não concessão do passe-livre) e não por dever a uma ordem. Do mesmo modo, o Tribunal destaca como relevante a postura de liberdade através da ação moral dada a priori e não por questões pessoais. Este tipo de liberdade refletiria uma concepção formal.

Em oposição ao pensamento de natureza kantiana estaria o particularismo. A concepção particularista aristotélica leva em consideração a pluralidade e diversidade como algo intrínseco a existência do Estado. Esta miscelânea plural conduz ao desenvolvimento de facções que, por possuírem objetivos particulares, podem gerar conflituosidade.

$\mathrm{Na}$ controvérsia posta a resolução pelo Judiciário verifica-se que é possível identificar uma busca discursiva de elementos hegelianos de construção de uma consciência ética. A relatora parte do ser para construir sua argumentação ao descrever a importância de serem assegurados direitos a pessoas com deficiências, examina o contexto social informando que, segundo a ONU, aproximadamente $10 \%$ da população mundial possui algum tipo de deficiência, sendo que a maior parte destas pessoas ( 8 em cada 10) concentram-se em países em desenvolvimento.

$\mathrm{Na}$ ausência de uma aquisição natural da Ideia do Bem, o Estado através de suas instituições busca conduzir os grupos ou facções ao seu alcance, foi o que ocorreu com a introdução de medidas para inserir na sociedade o grupo das pessoas portadoras de deficiência. Já que a naturalidade querida por Kant é impossível, tanto que, mesmo o Estado direcionando os grupos a aquisição da Ideia do Bem, estes se debatem e utilizam as instituições para tentar não cumprir com este princípio buscando interesses pessoais.

Essa contradição existente nas diversas facções que compõem a sociedade atual é perceptível inclusive nas instituições. Põe-se, assim, uma controvérsia deste tipo na decisão aqui trazida: o discurso usado pelo Judiciário brasileiro é incompatível com suas decisões. Isto significa que ao disciplinar o conteúdo do princípio da igualdade como algo composto pelo ideal de justiça, que por sua vez, deveria ser construído empiricamente pela sociedade, o Judiciário deveria buscar de maneira interdisciplinar os elementos que compõem esse arcabouço. Mas não, analisa dados singulares, a partir de um viés jurídico abstrato e generalizador, desprezando elementos empíricos na análise do caso concreto, aproximando-se muito mais da vertente kantiana do que da hegeliana. 
A busca pela moderação hegeliana, o meio-termo como virtude, assim como a liberdade como possibilidade do sujeito de livrar-se das inclinações e contingências do mundo sensível, embora identificáveis na decisão e associadas a alguma forma de tentativa de correição nas escolhas, não fundamentam a aplicação adequada da proporcionalidade como máxima na solução de problemas de colisão de princípios.

Indicativo de uma tendência do Judiciário ao se deparar com colisões de princípios, ao se avaliar a constitucionalidade, a relatora parte da análise do preâmbulo constitucional indicando os valores eleitos pela sociedade brasileira de maneira abstrata, afirmando ao final que há no texto constitucional a previsão do princípio da solidariedade e que este deve funcionar como cânone interpretativo da igualdade.

No âmbito de seleção das possibilidades jurídicas, a colisão de princípios impõe um raciocínio completamente diverso. Um primeiro âmbito de análise indica que, na colisão, o princípio que não prepondere não sofrerá nenhum tipo de juízo de invalidez, restrição geral ou incompatibilidade com o conjunto normativo (nenhuma forma, nesse sentido, de solução universalista ou de (in)aplicabilidade a priori). Haverá apenas uma construção de precedência, condicionada a determinadas situações, de um principio sobre outro.

Partindo da lei de colisão e do sopesamento, na construção de um modelo de análise de decisões judiciais imporia após a identificação de princípios contraditórios no caso concreto, a identificação de condições de precedência, que não pode ser feita através de simples opiniões, mas deve corresponder a um resultado submetido às regras e formas apresentadas pela teoria da Argumentação Jurídica e, por fim as escolhas das condições de maior peso, levando-se em conta as possibilidades fáticas e jurídicas sempre. Dessa forma, numa eventual avaliação, como a feita no presente artigo, seria possível identificar o grau de coerência entre as etapas e os possíveis níveis de justificação da opção decisória, sem afirmar apenas que é uma construção opinativa.

\section{REFLECTIONS ON THE WEIGHTING OF THE RIGHT TO EQUALITY IN RELATION TO THE PRINCIPLE OF PROPERTY AND FREE ENTERPRISE: AN EXAMINATION (BRAZILIAN SUPREME COURT) OF THE ADI N. 2,649/DF}

\section{Abstract}

This article aims to analyze the ruling content where there was a collision of principles, relating its elements to the Kantian and Hegelian aspects. In May 2008 the Brazilian Supreme 
Court (Supremo Tribunal Federal - STF) ruled by majority rejected one action of unconstitutionality proposed by ABRATI - Brazilian Association of Interstate Transport Companies, Intercity and International Passenger in the face of Law 8,899/1994 granted two seats with free pass for people with disabilities. Seeking to structure an argument by deductive method, observing the spatial boundaries that circumscribe the article format, the theories of the above authors outlines are treated. After the article will evaluate the proportionality of the application solution. Finally, reflect on the issues theoretical proposals and the decision specifically carried out by the Brazilian Supreme Court $(S T F)$.

Keywords: Law - Principles - Proportionality - Weighing - Equality

\section{REFERÊNCIAS BIBLIOGRÁFICAS}

AGUILO REGLA, Josep. Sobre Derecho y Argumentación. In: Sobre Derecho y Argumentación. Palma (Mallorca): Lleonard Muntaner, 2008.

ALEXY, Robert. Teoria de La argumentación jurídica. Tradução de Manuel Atienza e Isabel Espejo. 2. ed. Madrid: Centro de Estudos Políticos y Constitucionales, 2007.

Teoria dos Direitos Fundamentais. Tradução de Virgílio Afonso da Silva. 5. ed. alemã, São Paulo: Malheiros, 2008.

Teoria dos Direitos Fundamentais. Tradução de Virgílio Afonso da Silva. 5 ed. alemã, 2. ed. brasileira, São Paulo: Malheiros, 2015. 1988.

Sistema jurídico, princípios y razón práctica. Tradução de Manuel Atienza. DOXA 5.

Constitutional Rights and Proportionality. Revus [Online], 22 - 2014, Online since 25 June 2014, connection on 08 July 2014. Disponível em: http://revus.revues.org/2783 ; DOI : 10.4000/revus.2783. Acesso em: 12/02/2015.

The argument from Injustice. A reply to Legal Positivism. Translated by Bonnie Litschewski Pauson and Stanley L. Paulson. Oxford. : Oxford University Press, 2010.

Conceito e Validade do Direito. Tradução Gercélia Batista de Oliveira Mendes. São Paulo: Martins Fontes, 2011.

BRASIL, Supremo Tribunal Federal. ADI2.649/DF. Ação direta de inconstitucionalidade: Associação brasileira das empresas de transporte rodoviário intermunicipal, interestadual e internacional de passageiros - ABRATI.[...] Relatora: Ministra Carmem Lúcia. Requerente: ABRATI - Associação das empresas de transporte rodoviário intermunicipal, interestadual e internacional de passageiros. Requerido: Presidente da República. Julgado em 08/05/2008. Disponível em: http://redir.stf.jus.br/paginadorpub/paginador.jsp?docTP $=\mathrm{AC} \&$ docID=555517. Acesso em: 23/03/2016.

BUSTAMANTE, Thomas da Rosa de. Teoria do Direito e Decisão Racional. Temas de teoría da argumentação jurídica. Rio de Janeiro: Renovar, 2008.

CASTRO, Marcus Faro de. Política e relações internacionais: fundamentos clássicos. Brasília: Universidade de Brasília, 2005.

FIGUEROA, ALFONSO G. La Teoría del Derecho en tiempos de Constitucionalismo. In: CARBONELL, Miguel. Neoconstitucionalismo(s). 2. ed., Madrid: Trotta. 2005. 
HEGEL, Georg W.Friedrich. Princípios da Filosofia do Direito. Tradução de Orlando Vitorino. São Paulo: Martins Fontes, 2000.

KANT, Immanuel. Fundamentação da Metafísica dos Costumes e Outros Escritos. Tradução de Leopoldo Holzback. São Paulo: Martin Claret, 1997.

PIETRO SANCHÍS, Luis P. Neoconstitucionalismo y ponderación judicial. In: CARBONELL, Miguel. Neoconstitucionalismo(s). 2. ed., Madrid: Trotta. 2005.

POCOCK, J. G. A. The Machiavellian Moment: Florentine Political Thought and the Atlantic Republican Tradition. Princeton: Princeton University Press, 1975.

RÖD, W. O caminho da filosofia: dos primórdios até o século XX. Tradução de Maurício Mendonça Cardozo, Caio Heleno da Costa Pereira e Roniere Ribeiro do Amaral. v.02, Brasília: $\mathrm{UnB}, 2008$.

ROESLER, Cláudia R. Direito e Argumentação no Pensamento de Manuel Atienza, Rio de Janeiro: Lumen Juris, 2007.

Trabalho enviado em 25 de março de 2016.

Aceito em 16 de junho de 2016. 